\title{
SYSTEMATIC REVIEW AND META-ANALYSIS OF PREVALENCE OF SARCOPENIA IN POST ACUTE INPATIENT REHABILITATION
}

Systematic Review and Meta-analysis of Prevalence of Sarcopenia in Post Acute Inpatient

Rehabilitation.

Irina Churilov MBBS FAFRM (RACP)

Department of Rehabilitation, St Vincent's Hospital Melbourne, 41 Victoria Pde, Fitzroy, Victoria 3065, Australia

ORCHID 0000-0002-0218-5622

Irina.churilov@gmail.com

Leonid Churilov BSc(Hons) PhD

Statistics and Decision Analysis Academic Platform, Melbourne Brain Centre (The Florey Institute of Neuroscience and Mental Health), 245 Burgundy St, Heidelberg 3084, Victoria, Australia

Leonid.churilov@gmail.com

Richard J Maclsaac BSc(Hons) PhD MBBS FRACP

Department of Endocrinology and Diabetes, St Vincent's Hospital Melbourne, 41 Victoria Pde, Fitzroy, Victoria 3065, Australia

r.macisaac@unimelb.edu.au

Elif I Ekinci MBBS FRACP PhD

Department of Medicine, The University of Melbourne, Austin Health, Burgundy St, Heidelberg 3084, Victoria, Australia

Elif.ekinci@unimelb.edu.au

Corresponding author details:

Dr Irina Churilov

Irina.churilov@gmail.com

Department of Rehabilitation, St Vincent's Hospital Melbourne, 41 Victoria Parade, Fitzroy, VIC 3165, Australia

$\mathrm{Ph}+61409528523$ 
Key words: sarcopenia, rehabilitation, inpatient rehabilitation, subacute care

Acknowledgments:

Irina Churilov acknowledges the support of the Australian Commonwealth Government through the Australian Government Research Training Scholarship.

The Florey Institute of Neuroscience and Mental Health acknowledges the strong support of the Victorian Government and in particular the funding from the Operational Infrastructure Support Grant.

We also acknowledge the constructive feedback from the three anonymous reviewers of this paper.

\section{Mini Abstract}

Sarcopenia is associated with poor function and increased risk of falls and disability. This work reports a systematic review and metaanalysis of prevalence of sarcopenia in post acute inpatient rehabilitation. Sarcopenia is found to be present in approximately $50 \%$ of rehabilitation patients and its prevalence may vary with admission diagnosis.

\section{Abstract}

Purpose: To conduct a systematic review and metaanalysis of reported prevalence of sarcopenia in post acute inpatient rehabilitation.

Methods: Systematic review conducted according to PRISMA guidelines (PROSPERO registration number CRD42016054135). Databases searched: MEDLINE, EMBASE, Cochrane Database of Systematic Reviews, Cochrane Central Register of Controlled Trials (CENTRAL), Cochrane Methodology Register, CINAHL. Studies considered: published January 1988 - February 2017. Key terms: 'sarcopenia' AND 'inpatient rehabilitation' OR 'rehabilitation' AND/OR 'prevalence'. Abstracts and subsequently full studies reporting sarcopenia prevalence in adults admitted to rehabilitation reviewed irrespective of design, provided sarcopenia diagnosis included at least assessment of muscle mass. Random effect meta-analysis was conducted. Methodological quality assessment: Agency for Healthcare Research and Quality, US Department of Health and Human Services tool (MORE tool); Joanna Briggs Institute Prevalence Critical Appraisal Tool.

Results: 426 studies identified during initial search, 399 excluded after reviewing titles and abstracts, 21 full text articles reviewed; six studies met inclusion criteria. Patient populations: after hip fracture (five studies), general deconditioning (one study). Identified sarcopenia prevalence ranged from 0.28 to 0.69 . Pooled sarcopenia prevalence obtained with random effect meta-analysis: $0.56(95 \% \mathrm{Cl}$ 0.46-0.65), heterogeneity $12=92.9 \%$. Main quality shortcomings: lack of reporting of inter- and intrarater reliability, lack of generalizability to other rehabilitation populations.

Conclusions: Original research examining sarcopenia prevalence in inpatient rehabilitation is scarce. Patient populations studied to date are not representative of general rehabilitation population with regard to both age and admission diagnoses. Sarcopenia may be present in approximately half of rehabilitation patients and its prevalence may vary with admission diagnosis. 


\section{Background}

Sarcopenia is condition that is associated with a number of adverse health conditions and outcomes. These include an increased risk of falls and poor physical status in the elderly [1-4], as well as cognitive impairment [5]. It is closely linked to frailty, with physical function impairment being part of the phenotype of both conditions $[6,7]$. Sarcopenia also has shared pathogenesis with and is associated with a higher prevalence of osteoporosis $[8,9]$. This has led to the introduction of the term 'osteosarcopenia' [10], which may facilitate better prevention and treatment of these conditions and reduce the adverse consequences of falls, fractures and disability. Sarcopenia has been a focus of sustained research effort in the recent times and the number of publications on sarcopenia in PubMed has grown exponentially since 1993 [11]. In late 2016, sarcopenia was recognized as an independent medical condition by the International Classification of Diseases, Tenth Revision, Clinical Classification (ICD-10-CM) code, emphasizing its clinical significance.

Establishing the diagnosis of sarcopenia remains a matter of vigorous debate, with a number of different diagnostic criteria used in the literature [1,12-17]. While all consensus definitions of sarcopenia published after 2010 include both muscle mass and function in the diagnosis $[1,16,17]$, some authors use muscle mass on its own in order to define sarcopenia [18-20]. There is a number of specific modalities of measuring muscle mass (such as magnetic resonance imaging, computerized tomography, Dual-energy X-ray absorptiometry and body impedance analysis) and muscle function (such as grip strength, gait speed and Short Physical Performance Battery) used by researchers, with a number of cut off points to diagnose sarcopenia used for both muscle mass, gait and grip strength $[21,22]$.

Although multiple studies have demonstrated that sarcopenia is highly prevalent in the elderly $[17,21]$, its prevalence in inpatient rehabilitation population remains unclear. In post acute care, inpatient rehabilitation is aimed at maximizing a patient's function prior to discharge from hospital by use of an intensive daily therapy program. Since sarcopenia is known to be associated with reduced functional status, it may be associated with slower patients' progress in rehabilitation, although this to date, has only been studied in small groups of older patients [23,24]. Early identification and treatment of patients with sarcopenia may allow for more specific therapeutic intervention, possibly leading to better progress in rehabilitation, however studies demonstrating both the prevalence and outcomes of sarcopenia specifically in the rehabilitation setting are necessary.

\section{Objective}

The objective of this study was to conduct a systematic review and meta-analysis of reported prevalence of sarcopenia in inpatient rehabilitation.

\section{Methods}

The systematic review was conducted according to PRISMA guidelines [25]. The study was registered on PROSPERO International prospective register of systematic reviews database (registration number CRD42016054135).

Data sources 
The electronic bibliographic databases searched were MEDLINE, EMBASE, The Cochrane Library (Cochrane Database of Systematic Reviews, Cochrane Central Register of Controlled Trials (CENTRAL), Cochrane Methodology Register) and CINAHL. Reference lists of relevant retrieved studies were also checked for further studies.

\section{Study selection}

The search strategy included a combination of appropriate MeSH and other free-text terms including the following key words: 'sarcopenia', 'inpatient rehabilitation', 'rehabilitation' and 'prevalence'. Studies published between January 1988 (chosen because the term 'sarcopenia' was coined by Rosenberg et al [26] in 1989) and February 2017 were sought. The search was restricted to studies in humans. There was no language restriction for the searches provided the abstracts were available in English. Abstracts and subsequently selected full studies reporting the prevalence of sarcopenia in adults admitted to inpatient rehabilitation were reviewed irrespective of design, as long as the diagnosis of sarcopenia included at least the assessment of muscle mass.

\section{Data extraction}

Titles and abstracts of studies were retrieved using the search strategy and those from additional sources were screened to identify studies that potentially meet the inclusion criteria outlined above. The full texts of these potentially eligible studies were retrieved and assessed for eligibility. A standardised form was used to extract data from the included studies for assessment of study quality and evidence synthesis. Extracted information included the following: study setting, study population, participant demographics and baseline characteristics, method of sarcopenia diagnosis, and study methodology. Two review authors extracted data independently. Interrater agreement between reviewers was assessed using Cohen's Kappa. If identified, any discrepancies were resolved through discussion.

\section{Data analysis}

Random effect meta-analysis of prevalence reported at the study level was conducted using a Generalised Linear Mixed Model with exact 95\% confidence intervals implemented in Stata 13IC (StataCorp, College Station, TX, USA) module metaprop. Heterogeneity was assessed using the $I^{\wedge} 2$ statistics and Chi-square test for heterogeneity. A rough guide for interpretation of thresholds for ।^2 was adopted from Cochrane handbook [27] section 9.5.2. In studies where more than one diagnostic criterion was used to diagnose sarcopenia on the same study sample, the criterion used more frequently by other included studies was chosen for the main analysis. The analysis was then repeated with alternative diagnostic criterion included to understand the robustness of the main findings. Subgroup analyses were to be undertaken if sufficient number of studies using particular combinations of diagnostic criteria were identified.

Methodological quality of included studies was assessed using MORE tool [28] and Joanna Briggs Institute Prevalence Critical Appraisal Tool [29].

\section{Results}

Figure 1 shows the exclusion flow chart. Of the 426 studies identified through the search, 399 were excluded after reviewing the titles and abstracts. The main reasons for exclusion were that the paper was a review, a case report or did not address the study question. 27 papers were identified as suitable for further review of full text. Of these, 21 papers were excluded because the study either 
did not report the outcome of interest or was the repeated study done on the same population. Six original research studies met the inclusion criteria [18-20,23,30,31]. There was no disagreement between the reviewers regarding the inclusion criteria (Cohen's Kappa $=1,95 \% \mathrm{Cl}: 1,1$ ). The main characteristics of these studies are summarised in Table 1 and described below.

\section{Target population characteristics}

Five out of six studies investigated patients admitted for rehabilitation following hip fractures; of these, two included women only with hip fractures. Three studies excluded patients whose fractures were due to cancer or major trauma, and one study specified that in order to be eligible for inclusion in the study, the patients' hip fracture had to be surgically managed. One study specifically excluded patients with diagnoses of 'disabling diseases that could directly affect muscle weakness (such as neurological diseases, hip fractures or amputations)'. Three studies specifically excluded patients younger than 60, 65 and 70 years respectively, and the mean ages in all studies ranged from 73.8 to 84.6 years. None of the studies included a full range of diagnoses commonly encountered in subacute inpatient rehabilitation population.

\section{Method of sarcopenia diagnosis}

A wide variety of sarcopenia diagnostic criteria were used in the identified studies (Table 1). Three studies used both muscle mass and function for diagnosis. Of these, two studies used the European Working Group on Sarcopenia in Older People (EWGSOP) algorithm [23,30], with DEXA and grip strength measured in one, and body bioimpedance (BIA) and grip strength in the other. The remaining study used the Asian Working Group for Sarcopenia (AWGS) algorithm [31], measuring DEXA and grip strength. Neither of the studies assessed patients' mobility, with one author commenting this was 'not feasible'.

The remaining three studies used muscle mass only for diagnosis of sarcopenia and measured the muscle mass by DEXA scanning. Three different diagnostic criteria for cut off points were used: The Foundation for the National Institutes of Health algorithm in one study [18], New Mexico Elder Health algorithm in another [20], and both New Mexico Elder Health algorithm and Rochester, Minnesota method in the third one [19], which therefore reported two different results for sarcopenia incidence on the same study sample. Since the New Mexico Elder Health algorithm was applied overall in more other studies than the Rochester, Minnesota one, we used the results obtained from the New Mexico Elder Health algorithm reported in Di Monaco et al [19] for the main meta-analysis of prevalence of sarcopenia.

\section{Prevalence of sarcopenia in inpatient rehabilitation}

The prevalence of sarcopenia in identified individual studies ranged from 0.28 ( $95 \% \mathrm{Cl} 0.25-0.32$, Rochester, Minnesota diagnostic criteria used in Di Monaco et al [19]) to 0.69 (95\% Cl 0.63-0.75 [20]).

Pooled prevalence of sarcopenia obtained with random effect meta-analysis, using New Mexico Elder Health criteria for Di Monaco et al [19] for consistency with Di Monaco et al [20], was 0.56 (95\% $\mathrm{Cl} 0.46-0.65)$ (Figure 2). The percentage of the variability in effect estimates due to heterogeneity rather than sampling error $I^{\wedge} 2$ was $92.9 \%$ (Chi-squared heterogeneity $p<0.001$ ), indicative of substantial heterogeneity.

On robustness analysis, using Rochester, Minnesota criteria for Di Monaco et al [19], pooled prevalence of sarcopenia was $0.49(95 \% \mathrm{Cl} 0.34-0.64)$, with the percentage of the variability in effect 
estimates due to heterogeneity $I^{\wedge} 2=97.3 \%$ (Chi-squared heterogeneity $p<0.001$ ), also indicative of substantial heterogeneity (Supplementary Fig 1 ).

\section{Subgroup analyses of prevalence of sarcopenia in inpatient rehabilitation}

Studies were further subdivided based on whether muscle mass only or mass and function were used to diagnose sarcopenia. In the studies that used both muscle mass and function for diagnosis, pooled prevalence of sarcopenia was estimated to be $0.58(95 \% \mathrm{Cl} 0.45-0.72)$, with the percentage of the variability in effect estimates due to heterogeneity $\mathrm{I}^{\wedge} 2=88.1 \%$ (Chi-squared heterogeneity $p<0.001$ ), indicative of substantial heterogeneity (Fig 3a). As no studies in this subgroup used more than one diagnostic criterion, no robustness analysis was performed.

In the studies that used only muscle mass for diagnosis, using New Mexico Elder Health criteria for Di Monaco et al [19], pooled prevalence of sarcopenia was estimated to be 0.53 ( $95 \% \mathrm{Cl} 0.37-0.70)$, with the percentage of the variability in effect estimates due to heterogeneity $I^{\wedge} 2=96.2 \%$ (Chisquared heterogeneity $p<0.001$ ), indicative of considerable heterogeneity (Fig $3 b)$. On robustness analysis, using Rochester, Minnesota criteria for Di Monaco et al [19], pooled prevalence of sarcopenia to be 0.40 ( $95 \% \mathrm{Cl} 0.20-0.59)$, with the percentage of the variability in effect estimates due to heterogeneity $1^{\wedge} 2=97.4 \%$ (Chi-squared heterogeneity $p<0.001$ ), indicative of substantial heterogeneity (Supplementary Fig 2).

\section{Methodological quality and bias}

The methodological quality of identified studies was assessed using two different tools. The Joanna Briggs Institute Prevalence Critical Appraisal Tool developed by Munn et al [29] (Table 2) is a 10 item questionnaire. The two quality shortcomings identified using this questionnaire were failure to report the calculated sample size in five out of six studies, and no reporting of the details of numbers of eligible patients who were not recruited in three out of six studies. The Methodological Evaluation of Observational Research (MORE) - Observational Studies of Incidence and Prevalence of Chronic Diseases [28] is a more descriptive tool. Further quality shortcomings of individual studies identified using the MORE tool were the absence of reported intra- or interrater reliability in all studies.

\section{Discussion}

This literature search and meta-analysis demonstrated that studies examining the prevalence of sarcopenia in post acute inpatient rehabilitation focus on older patients and patients with a limited range of admission diagnoses (hip fractures and general deconditioning), and are therefore not representative of the general rehabilitation population both with regard to age and variety of admission diagnoses usually encountered in subacute rehabilitation [32]. While patients with hip fractures and general deconditioning do represent a significant proportion of rehabilitation inpatients, the prevalence of sarcopenia in other common rehabilitation diagnostic groups, such as patients after stroke, elective joint replacement, lower limb amputation, and spinal cord injury, remains unknown.

The prevalence of sarcopenia in the community is estimated to be $5-13 \%$ in $60-70$ year olds and 11 $50 \%$ in people older than 80 years [33]. We have demonstrated a higher prevalence of sarcopenia in the post acute inpatient rehabilitation setting of 0.56 , in a population with mean age ranging from 73.8 to 84.6 years, and here are several possible reasons as to why sarcopenia may be more prevalent in rehabilitation than in the community. Firstly, since sarcopenia is associated with greater risk of falls, disability and osteoporosis, a sarcopenic patient is more likely to sustain a hip fracture than a non sarcopenic patient. Further, such a patient can be hypothesized to be more likely to 
require rehabilitation rather than return directly to home due to greater functional impairment. Furthermore, prolonged hospitalisation may lead to occurrence of sarcopenia, especially when accompanied by periods of immobility and fasting. The hospitalised elderly individuals are also known to be at higher risk of malnutrition than non hospitalised elderly individuals [34], and high risk of malnutrition is associated with lower muscle mass in this population [35].

The lack of a single commonly accepted definition is a major limitation of research in the field of sarcopenia. Matters that are currently being debated include acceptable methods of measuring muscle mass, the cut off points for muscle mass, grip strength and gait speed; and whether gait speed should be considered for patients who are non ambulant due to conditions other than muscle weakness. Some studies have also assessed probability of sarcopenia using proxy measures such as calf circumference and functional measures [24,36]. Rehabilitation is a goal-oriented medical speciality where patients' functional performance is an important outcome of treatment. Hence the definitions that incorporate muscle mass and function may be most appropriate in this setting.

The differences between prevalence of sarcopenia in studies we identified could be partly explained by the different criteria used for the diagnosis. The dependence of prevalence of sarcopenia on the diagnostic method used is clearly seen in the study by Di Monaco et al [19], where the New Mexico Elder Health criteria (also used in Di Monaco et al [20]) estimated the prevalence of 0.67, while application of Rochester, Minnesota criteria on the same data estimated the prevalence of 0.28 . It is important to note that despite this difference in Di Monaco et al [19] estimations, there was no appreciable difference in the pooled prevalence obtained from two corresponding meta-analyses.

Another possible contributor to the differences between prevalence of sarcopenia in identified studies is the time from hip fracture or admission to the acute hospital and the measurement of muscle mass. In the hip fracture populations, Landi et al [18] reported the lowest time from admission to diagnosis of mean 3.8 days of acute admission plus up to 2 days from admission to rehabilitation to assessment for the study, and demonstrated the lowest prevalence of sarcopenia in the main metaanalysis. This finding may suggest that the incidence of sarcopenia during admission to hospital increases with increased length of stay, particularly in conditions that require a period of immobility such as hip fracture.

The interesting point of similarity between the prevalence of sarcopenia in studies that used muscle mass only and in studies that used both muscle mass and function is in line with the findings of Masanes et al [37], who demonstrated that it is the cut off points for muscle mass rather than the functional measures that have the greatest effect on sarcopenia prevalence.

As the prevalence of sarcopenia was found to be higher than in the community in the included studies, it can be hypothesized that it may be more prevalent in the younger rehabilitation population, as well as in the geriatric patients with diagnoses other than hip fractures and deconditioning, compared to respective demographic groups in the community. Since sarcopenia is known to negatively impact health outcomes of older, frail patients admitted to rehabilitation units, it will be beneficial to investigate its impact on the younger non frail population in this setting.

\section{Conclusions}

Sarcopenia may be present in about half of inpatient rehabilitation population. Original research examining the prevalence of sarcopenia in inpatient rehabilitation is scarce, and generalizability of these findings to inpatient rehabilitation populations not explicitly studied to date is expected to be 
limited due to differences in both age and admission diagnoses. The prevalence of sarcopenia in rehabilitation is likely to be higher than in comparable groups in the community. Further studies of prevalence, with less exclusions based on age or diagnosis, are needed.

\section{Conflict of interest.}

The authors have no conflict of interest to declare.

\section{References}

1. Cruz-Jentoft AJ, Baeyens J, Bayer J et al. Sarcopenia: European consensus on definition and diagnosis: Report of the European Working Group on Sarcopenia in Older People. Age Ageing. 2010; 39:412-23.

2. Beaudart C, Rizzoli R, Bruyere $O$ et al. Sarcopenia: Burden and challenges for Public Health. 2014. Archives of Public Health. Arch Public Heal. 2014; 72:45.

3. Phillips A, Strobl R, Vogt S, Ladwig KH et al. Sarcopenia is associated with disability status results from the KORA-Age study. Osteoporosis Int 2017; 28(7):2069-2079.

4. Scott D, Hayes A, Sanders KM, Aitken D et al. Operational definitions of sarcopenia and their associations with 5 -year changes in falls risk in community-dwelling middle-aged and older adults. Osteoporosis Int 2014; 25(1):187-193.

5. Chang K, Hsu T, Wu W et al. Association Between Sarcopenia and Cognitive Impairment: A Systematic Review and Meta-Analysis. J Am Med Dir Assoc. 2016; 17(12):1164.e7-1164.e15.

6. Cesari M, Landi F, Vellas, Bernabei R and Marzetti E. Sarcopenia and physical frailty: two sides of the same coin. Front Aging Neurosci 2014; 6:192.

7. Cooper C, Dere W, Evans W, Kanis JA et al. Frailty and sarcopenia: definitions and outcomes parameters. Osteoporosis Int 2012; 23(7):1839-1848.

8. He H, Liu Y, Tian Q, Papasian CJ et al. Relationship of sarcopenia and body composition with osteoporosis. Osteoporosis Int 2016; 27(2):473-482.

9. Binkley N, Krueger D and Buehring B. What's in a name revisited: should osteoporosis and sarcopenia be considered components of 'dysmobility syndrome? Osteoporosis Int 2013; 24:2955-2959.

10. Hirschfeld HP, Kinsella R and Duque G. Osteosarcopenia: where bone, muscle and fat collide. Osteoporosis Int 2017; 28(10):2781-2790.

11. Cao L, Morley J. Sarcopenia is recognized as an independent condition by an International Classification of Disease Tenth Revision, Clinical Modification (ICD-10-CM) Code. J Am Med Dir Assoc. 2016; 17(8):675-677.

12. Fielding RA, et al. Sarcopenia: an undiagnosed condition in older adults. Current consensus definition: prevalence, etiology, and consequences. International working group on sarcopenia. J Am Med Dir Assoc. 2011; 12:249-56.

13. Muscaritoli M, Anker S, Argiles J, Aversa Z et al. Consensus definition of sarcopenia, cachexia and pre-cachexia: joint document elaborated by Special Interest Groups (SIG) 'cachexiaanorexia in chronic wasting diseases' and 'nutrition in geriatrics'. Clin Nutr. 2010; 29:154-9.

14. Dam T, Peters K, Fragala M, Cawthon P et al. An evidence-based comparison of operational criteria for the presence of sarcopenia. J Gerontol A Biol Sci Med Sci. 2014; 69:584-90.

15. Morley J, Abbatecola A, Argiles J, Baracos V et al. Sarcopenia with limited mobility: an International Consensus. J Am Med Dir Assoc. 2011; 12:403-9.

16. Studenski S, Peters K, Alley D, Cawthon P et al. The FNIH sarcopenia project: rationale, study description, conference recommendations, and final estimates. J Gerontol A Biol Sci Med Sci. 2014; 69:547-58. 
17. Chen L, Liu L, Woo J, Assantachai P et al. Sarcopenia in Asia: Consensus Report of the Asian Working Group for Sarcopenia. J Am Med Dir Assoc. 2014; 15:95-101.

18. Landi F, Calvani R, Ortolani E, Salini S et al. The association between sarcopenia and functional outcomes among older patients with hip fracture undergoing in-hospital rehabilitation. Osteoporosis Int 2017; 28(5): 1569-1576.

19. Di Monaco M, Castiglioni C, Vallero F, Di Monaco R et al. Sarcopenia is more prevalent in men than in women after hip fracture: a cross sectional study of 591 inpatients. Arch Gerontol Geriatrics 2012; 55:e48-e52.

20. Di Monaco M, Vallero F, Di Monaco R, Tappero R. Prevalence of sarcopenia and its association with osteoporosis in 313 older women following a hip fracture. Arch Gerontol Geriatrics 2011; 52:71-74.

21. Cruz-Jentoft A, Landi F, Schneider S, Zuniga C et al. Prevalence of and interventions for sarcopenia in ageing adults: a systematic review. Report of the International Sarcopenia Initiative (EWGSOP and IWGS). Age Ageing. 2014; 43(6):748-59.

22. Bahat $G$, Tufan $A$, Tufan F, Kilic $C$ et al. Cut-off points to identify sarcopenia according to European Working Group on Sarcopenia in Older People (EWGSOP) definition. Clin Nutr 2016; 35(6):1557-1563.

23. Sanchez-Rodriguez D, Marco E, Miralles R, Fayos M et al. Sarcopenia, physical rehabilitation and functional outcomes of patients in a subacute geriatric care unit. Arch Gerontol Geriatrics 2014; 59:39-43.

24. Morandi A, Onder G, Fodri L, Sanniti A et al. The association between the probability of sarcopenia and functional outcomes in older patients undergoing in-hospital rehabilitation. J Am Med Dir Assoc 2015; 16(11)951-956.

25. Moher D, Liberati A, Tetzlaff J, Altman DG, The PRISMA Group (2009). Preferred Reporting Items for Systematic Reviews and Meta-Analyses: The PRISMA Statement. PLoS Med 2009; 6(6):e1000097.

26. Rosenberg I. Summary comments: epidemiological and methodological problems in determining nutritional status of older persons. Am J Clin Nutr. 1989; 50:1231-3.

27. Higgins J, Green S (editors). Cochrane Handbook for Systematic Reviews of Interventions Version 5.1.0 [updated March 2011]. The Cochrane Collaboration, 2011. Available from www.cochrane-handbook.org.

28. Shamliyan T, Kane R, Ansari M, Raman G et al. Methodological Evaluation of Observational Research (MORE) - Observational Studies of Incidence and Prevalence of Chronic Diseases (2011). Agency for Healthcare Research and Quality, US Department of Health and Human Services, publication No. 11-EHC008-EF).

29. Munn Z, Moola S, Riitano D, Lisy K. The development of a critical appraisal tool for use in systematic reviews addressing questions of prevalence. Int J Health Policy Manag 2014; 3(3):123-128.

30. Di Monaco M, Castiglioni C, De Toma E, Gardin L et al. Presarcopenia and sarcopenia in hipfracture women: prevalence and association with ability to function in activities of daily living. Aging Clin Exp Res 2015; 27:465-472.

31. Ho A, Lee M, Chan E, Ng H et al. Prevalence of pre-sarcopenia and sarcopenia in Hong Kong Chinese geriatric patients with hip fracture and its correlation with different factors. Hong Kong Med J 2016; 22:23-9.

32. The AROC Annual Report: The state of rehabilitation in Australia 2016.

33. Morley J. Sarcopenia: diagnosis and treatment. J Nutr Health Aging 2008; 12:452-6.

34. Kaiser MJ, Bauer JM, Ramsch C, Uter W et al. Frequency of malnutrition in older adults: a multinational perspective using the mini nutritional assessment. J Am Geriatr Soc 2010; 58(9):1734-8. 
35. Pierik VD, Meskers CGM, Van Ancum JM, Numans ST et al. High risk of malnutrition is associated with low muscle mass in older hospitalized patients - a prospective cohort study. BMC Geriatrics 2017; 17:118.

36. Ishii S, Tanaka T, Shibasaki K, Ouchi Y et al. Development of a simple screening test for sarcopenia in older adults. Geriatr Gerontol Int 2014; 14 (Suppl. 1): 93-101.

37. Masanes F, Lojano I, Luque X, Salva A et al. Cut-off points for muscle mass - not grip strength or gait speed - determine variations in sarcopenia prevalence. J Nutr Health Aging 2017; 21(7):825-829.

\section{Tables and Figures}

Figure 1. PRISMA exclusion flowchart

Table 1. Key characteristics of included studies

Figure 2. Prevalence of sarcopenia, all studies - Forest plot

Fig 3. Prevalence of sarcopenia: studies using for diagnosis:

a) Muscle structure and function

b) Only muscle structure

Supplementary Figure 1. Prevalence of sarcopenia, all studies, Rochester, Minnesota criteria for Di Monaco et al (2012) - Forest plot

Supplementary Figure 2. Prevalence of sarcopenia, studies using only muscle structure for diagnosis, RM criteria for Di Monaco et al (2012) - Forest plot

Table 2. Quality of included studies (from Munn et al, 2014) 
Table 1. Key characteristics of included studies

\begin{tabular}{|c|c|c|c|c|c|c|}
\hline $\begin{array}{l}\text { Study } \\
\text { (Country) }\end{array}$ & Design & $\begin{array}{l}\text { Method of } \\
\text { sarcopenia diagnosis }\end{array}$ & $\begin{array}{l}\text { Inpatient rehabilitation patient } \\
\text { type }\end{array}$ & Patient number & $\begin{array}{l}\text { Mean age in years } \\
\text { (SD) }\end{array}$ & $\begin{array}{l}\text { Days from fracture } \\
\text { to muscle mass } \\
\text { measurement }\end{array}$ \\
\hline $\begin{array}{l}\text { Di Monaco et } \\
\text { al, } 2015 \text { (Italy) }\end{array}$ & Prospective & $\begin{array}{l}\text { EWGSOP (DEXA and } \\
\text { handgrip) }\end{array}$ & $\begin{array}{l}\text { Women, hip fracture, no weakness } \\
\text { due to neurological disease, no } \\
\text { major trauma or bone cancer, no } \\
\text { arthroplasty, no acute concomitant } \\
\text { disease }\end{array}$ & $\begin{array}{l}\text { Sarcopenic } \\
\text { patients }-80 \\
\text { Presarcopenic } \\
\text { patients }-23 \\
\text { Patients with } \\
\text { normal muscle } \\
\text { mass }-35\end{array}$ & $\begin{array}{l}\text { Sarcopenic } \\
\text { patients }-81.3 \\
(7.5) \\
\text { Presarcopenic } \\
\text { patients }-73.8 \\
(5.5) \\
\text { Patients with } \\
\text { normal muscle } \\
\text { mass - } 78.9(7.7)\end{array}$ & $\begin{array}{l}\text { Normal muscle } \\
\text { mass - median } 18 \\
\text { (IQR 14.5-25) } \\
\text { Presarcopenia - } \\
\text { median } 18 \text { (IQR 14- } \\
\text { 21) } \\
\text { Sarcopenia -median } \\
18 \text { (IQR 14-25.5) }\end{array}$ \\
\hline $\begin{array}{l}\text { Sanchez- } \\
\text { Rodriguez et } \\
\text { al, } 2014 \\
\text { (Spain) }\end{array}$ & Prospective & $\begin{array}{l}\text { EWGSOP (BIA and } \\
\text { handgrip) }\end{array}$ & $\begin{array}{l}\text { Older than } 75 \text { years, no } \\
\text { neurological disease, hip fracture } \\
\text { or amputation ('disabling diseases') }\end{array}$ & 99 & $84.6(6.6)$ & Not applicable \\
\hline $\begin{array}{l}\text { Ho et al, } 2016 \\
\text { (Hong Kong) }\end{array}$ & Prospective & $\begin{array}{l}\text { AWGS (DEXA and } \\
\text { grip strength) }\end{array}$ & $\begin{array}{l}\text { Older than } 60 \text { years, 'operated' hip } \\
\text { fracture }\end{array}$ & 239 & 82.0 (not reported) & $\begin{array}{l}\text { Mean } 14 \text { (range 3- } \\
\text { 28) }\end{array}$ \\
\hline $\begin{array}{l}\text { Di Monaco et } \\
\text { al, } 2011 \text { (Italy) }\end{array}$ & Prospective & $\begin{array}{l}\text { DEXA (New Mexico } \\
\text { Elder Health study) }\end{array}$ & $\begin{array}{l}\text { Women, first hip fracture, no } \\
\text { cancer or major trauma }\end{array}$ & 313 & $79.7(7.4)$ & Mean 20.9 (SD 6.5) \\
\hline
\end{tabular}




\begin{tabular}{|c|c|c|c|c|c|c|}
\hline & $\begin{array}{l}\text { Sanchez- } \\
\text { Rodriguez et al, } \\
2014\end{array}$ & $\begin{array}{l}\text { Di Monaco et } \\
\text { al, } 2015\end{array}$ & $\begin{array}{l}\text { Ho et al, } \\
2016\end{array}$ & $\begin{array}{l}\text { Landi et al, } \\
2017\end{array}$ & $\begin{array}{l}\text { Di Monaco et } \\
\text { al, } 2012\end{array}$ & $\begin{array}{l}\text { Di Monaco et } \\
\text { al, } 2011\end{array}$ \\
\hline Was the sample representative of target population? & Yes & Yes & Yes & Yes & Yes & Yes \\
\hline $\begin{array}{l}\text { Were study participants recruited in an appropriate } \\
\text { way? }\end{array}$ & Unclear & Yes & Unclear & Unclear & Yes & Yes \\
\hline Was the sample size adequate? & Not reported & Not reported & $\begin{array}{l}\text { Not } \\
\text { reported }\end{array}$ & $\begin{array}{l}\text { Not } \\
\text { reported }\end{array}$ & Yes & Not reported \\
\hline $\begin{array}{l}\text { Were the study subjects and settings described in } \\
\text { detail? }\end{array}$ & Yes & Yes & Yes & Yes & Yes & Yes \\
\hline $\begin{array}{l}\text { Was the data analysis conducted with sufficient } \\
\text { coverage of identified sample? }\end{array}$ & Yes & Yes & Yes & Yes & Yes & Yes \\
\hline $\begin{array}{l}\text { Were objective, standard criteria used for the } \\
\text { measurement of the condition? }\end{array}$ & Yes & Yes & Yes & Yes & Yes & Yes \\
\hline Was the condition measured reliably? & Not reported & Not reported & $\begin{array}{l}\text { Not } \\
\text { reported }\end{array}$ & $\begin{array}{l}\text { Not } \\
\text { reported }\end{array}$ & Not reported & Not reported \\
\hline Was there appropriate statistical analysis? & Yes & Yes & Yes & Yes & Yes & Yes \\
\hline $\begin{array}{l}\text { Are all important confounding } \\
\text { factors/subgroup/differences identified and } \\
\text { accounted for? }\end{array}$ & Yes & Yes & Yes & Yes & Yes & Yes \\
\hline $\begin{array}{l}\text { Were subpopulations identified using objective } \\
\text { criteria? }\end{array}$ & $\mathrm{N} / \mathrm{A}$ & N/A & N/A & N/A & N/A & N/A \\
\hline
\end{tabular}




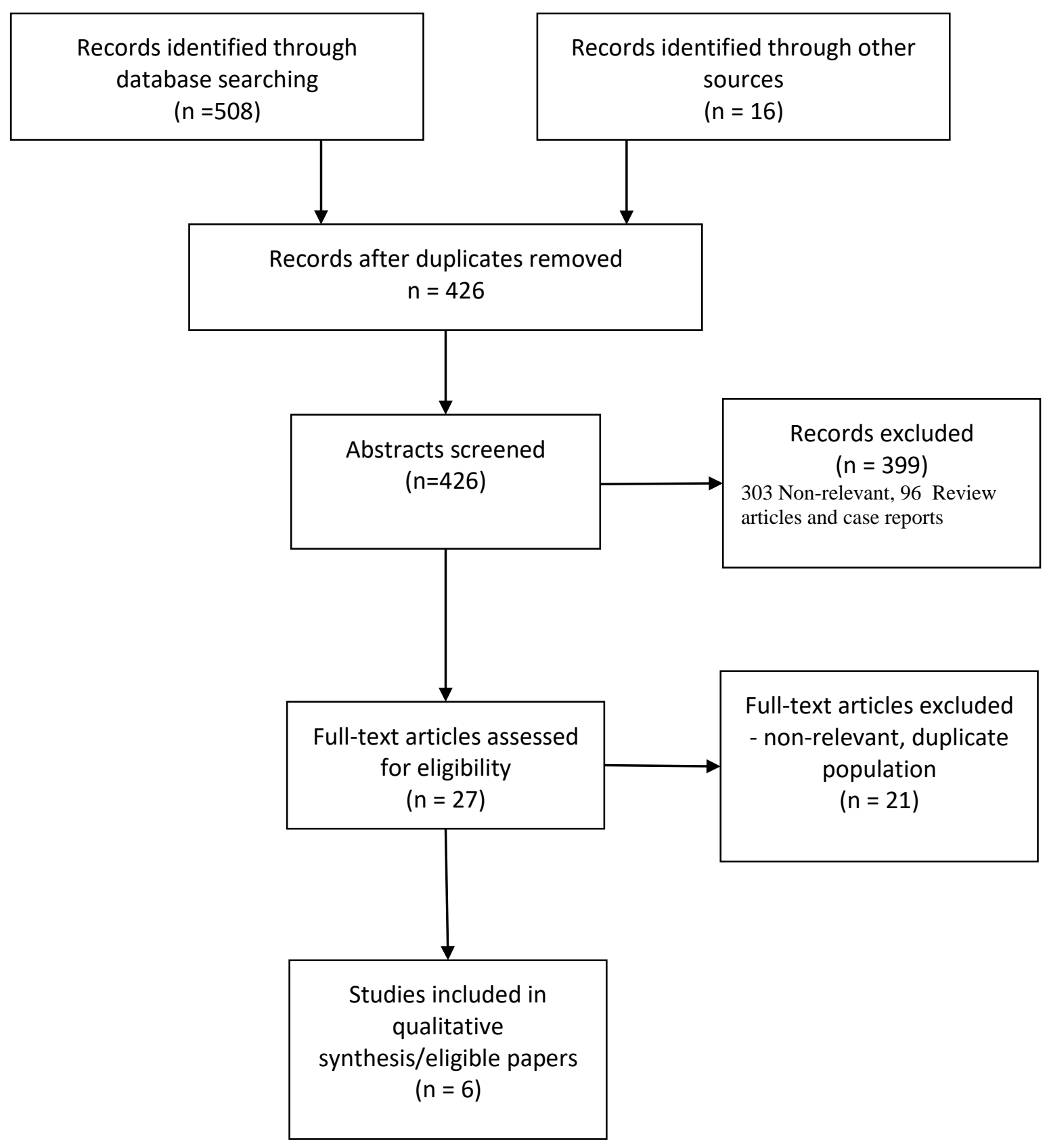




\section{Prevalence of sarcopenia}

Study

Di Monaco et al. (2011)

Di Monaco et al. (2012)

Sanchez-Rodriguez et al. (2014)

Di Monaco et al. (2015)

Ho et al. (2016)

Landi et al. (2017)

Overall $\left(I^{\wedge} 2=92.9 \%, p=0.000\right)$
ES $(95 \% \mathrm{Cl})$

$0.58(0.52,0.63)$

$0.67(0.63,0.71)$

$0.46(0.36,0.57)$

$0.58(0.49,0.66)$

$0.69(0.63,0.75)$

$0.34(0.26,0.43)$

$0.56(0.46,0.65)$ 


\section{Prevalence of sarcopenia}

Study

ES $(95 \% \mathrm{Cl})$

Sanchez-Rodriguez et al. (2014)

Di Monaco et al. (2015)

Ho et al. (2016)

Overall $\left(I^{\wedge} 2=88.1 \%, p=0.000\right)$

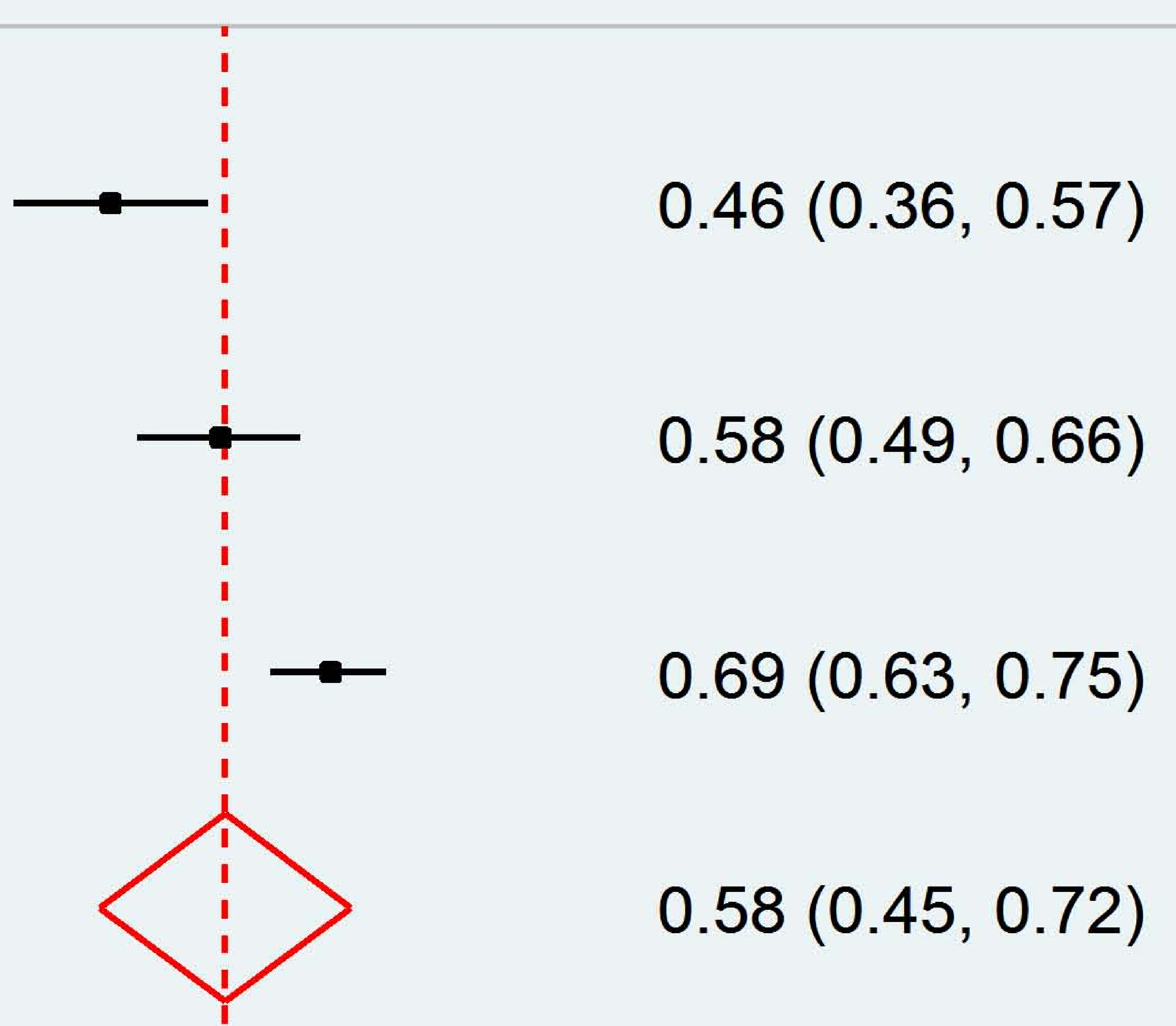




\section{Prevalence of sarcopenia}

Study

ES $(95 \% \mathrm{Cl})$

Di Monaco et al. (2011)

Di Monaco et al. (2012)

Landi et al. (2017)

Overall $\left(I^{\wedge} 2=96.2 \%, p=0.000\right)$

$0.58(0.52,0.63)$

$0.67(0.63,0.71)$

$0.34(0.26,0.43)$

$0.53(0.37,0.70)$

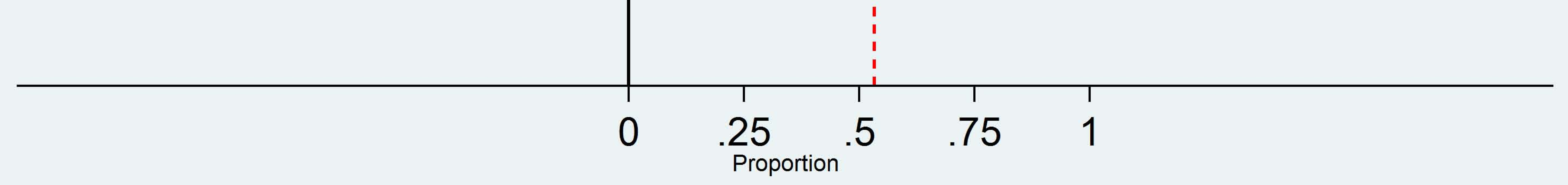

